\title{
Cartographying the real metropolis: A proposal for a data- based planning beyond the administrative boundaries
}

\author{
Juan R. Selva-Royo ${ }^{1}$, Nuño Mardones ${ }^{1}$, Alberto Cendoya ${ }^{2}$ \\ ${ }^{1}$ School of Architecture, Department of Theory and Design, University of Navarra. Spain \\ ${ }^{2}$ Navarra Center for International Development, University of Navarra Campus. Spain \\ E-mail: jrselva@unav.es,nmardones@unav.es, \\ cendoya.alberto@gmail.com
}

\begin{abstract}
Nowadays, there is a great gap between the functional reality of urban agglomerations and their planning, largely because of the traditional linkage of urban management to the administrative limits inherited from the past. It is also true that the regulation of urban activities, including census and statistical information, requires a closer view of its citizens that can only be addressed from the municipal level. In any case, it is clear that the metropolitan delimitation has met useful but often ethereal or exclusionary criteria (economic or labor patterns, functional areas...), which become disfigured by an administrative reality that does not always correspond to the real metropolis. This paper, aware of the new cartographic possibilities linked to the big data-CORINE Land Cover, SIOSE, multi-sector digital atlases (in many cases referred to the urban extent, etc.) and other open system platforms - explores the evidence that might base a new objective methodology for the delimitation and planning of large urban areas. Indeed, what if basic data for cities would arise not from administrative entities but from independent outside approaches such as satellite imagery? What if every single sensing unit (every citizen, company, building or vehicle) directly issued relevant and dynamic information without going through the municipal collection? Finally, the research analyzes the eventual implications of this databased planning with administrative structures and urban planning competencies in force through some current case studies, with the purpose of achieving a more efficient and clear metropolitan governance for our planet.
\end{abstract}

Keywords: Data planning, metropolitan areas, big data, urban extent, good governance

\section{Introduction}

The increasing share of the global urban population has recently generated a growing interest in the study of metropolitan areas (United Nations, 2015). The quantification of areas and densities, as well as the extent of the urban footprint have been a subject of study in recent literature (Angel, 2016), in which the extent of urban agglomerations and even the definition of the 'urban' itself has been questioned (Brenner and Schmid, 2014).

In Spain, valuable information about large cities is available, through documents such as the publication Áreas Urbanas +50 (Ministerio de Fomento, 2013), or the numerous research papers on urban systems and the delimitation of metropolitan areas (Roca Cladera et al., 2012). All of them have in common their statistical nature - for example, making use of the 2011 census data of residence and work mobility and the identification of a minimum indivisible and unquestionable unit: the municipality. However, there is usually a mismatch between the geographical delimitation of these metropolises and the scope of the planned planning instruments, which are often nonexistent (Hildenbrand, 2017). This generates a dysfunction that has its root in the fact that social sciences tend to use the administrative 
Datos de Ocupación de SUelo 1987-2006 (CORINE LAND COVER)

Mapa 1. Evolución de las superficies artificiales 1987-2006
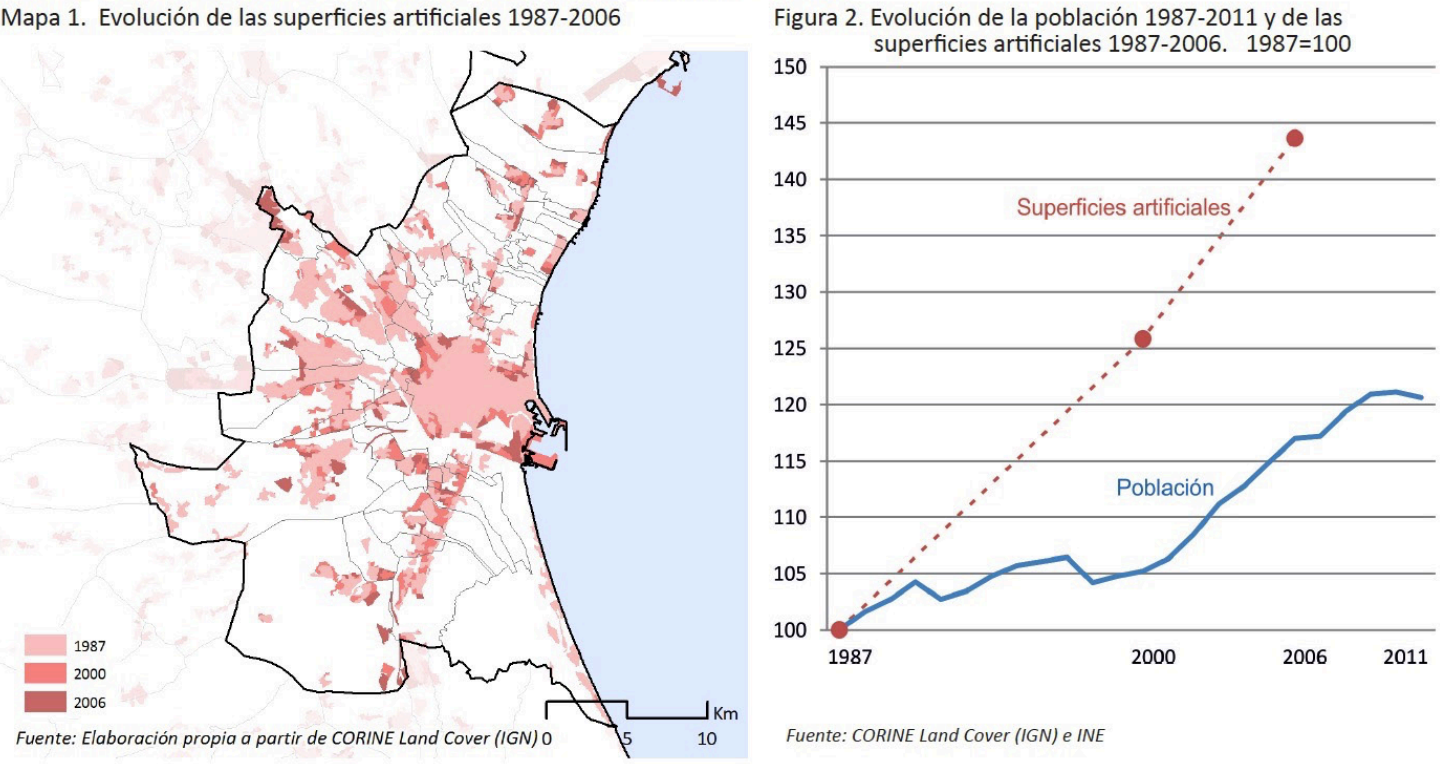

Figure 1. Valencia Urban Area delimitation obtained from diverse statistical data, finally covering 45 municipalities (Ministerio de Fomento, 2013).

municipal limits as a given object, often ignoring the reality and functionality of these metropolitan areas as a whole.

In this sense, the Valencian case is very relevant. Currently, the process of drawing up a thorough and comprehensive Metropolitan Territorial Action Plan for Valencia (PATEVAL) is underway. According to the Territorial Strategy of the Region of Valencia (ETCV), the draft of the plan takes into account diverse scenarios of delimitation of the metropolitan area, which reveals a worrying lack of definition in the starting point. Thus, the ETCV indicates an Integrated Urban Area of 58 municipalities according to basic criteria of interaction by proximity of uses in contiguous municipalities. In the other hand, if the commuting relations and physical continuity are taken into account, the result is a total of 76 municipal terms. Furthermore, recent studies based on surveys of intermunicipal mobility extend the metropolitan area to a total of 80 local constituencies (Feria Toribio and Martínez Bernabeu, 2016).

This mismatch not only affects the metropolitan delimitation, but also generates a frequent lack of coordination between the local and supramunicipal planning policies. In this regard, the inconsistencies of municipal boundaries are worth noting for cities such as
San Sebastián in which urban functional area transcend even the national Spanish border, generating a metropolitan area between two countries.

It is necessary understand that the term metropolis (which means mother city) was originally conceived as a relational concept where political, cultural and even military relationships were established. Nowadays, new variables derived from the productive model and economic relationships (mobility and work policies, territorial delocalization, digital connectivity) deserve to be included in this mix. Metropolitan reality transcends historically established administrative boundaries, often functionally obsolete, and its delimitation should respond to truly relevant information instead of to the sum of some administrative boundaries.

Metropolitan delimitation criteria in Europe The Spanish metropolises are integrated in the European Cities project (Urban Audit), Eurostat's urban data collection. In it, the city is defined as "a local administrative unit (LAU) where the majority of the population lives in an urban center of at least 50000 inhabitants". Two other units are also defined, the Functional Urban Area - formerly known as larger urban zone (LUZ) - consisting of "a city and its commuting zone", and the Greater City as "an 

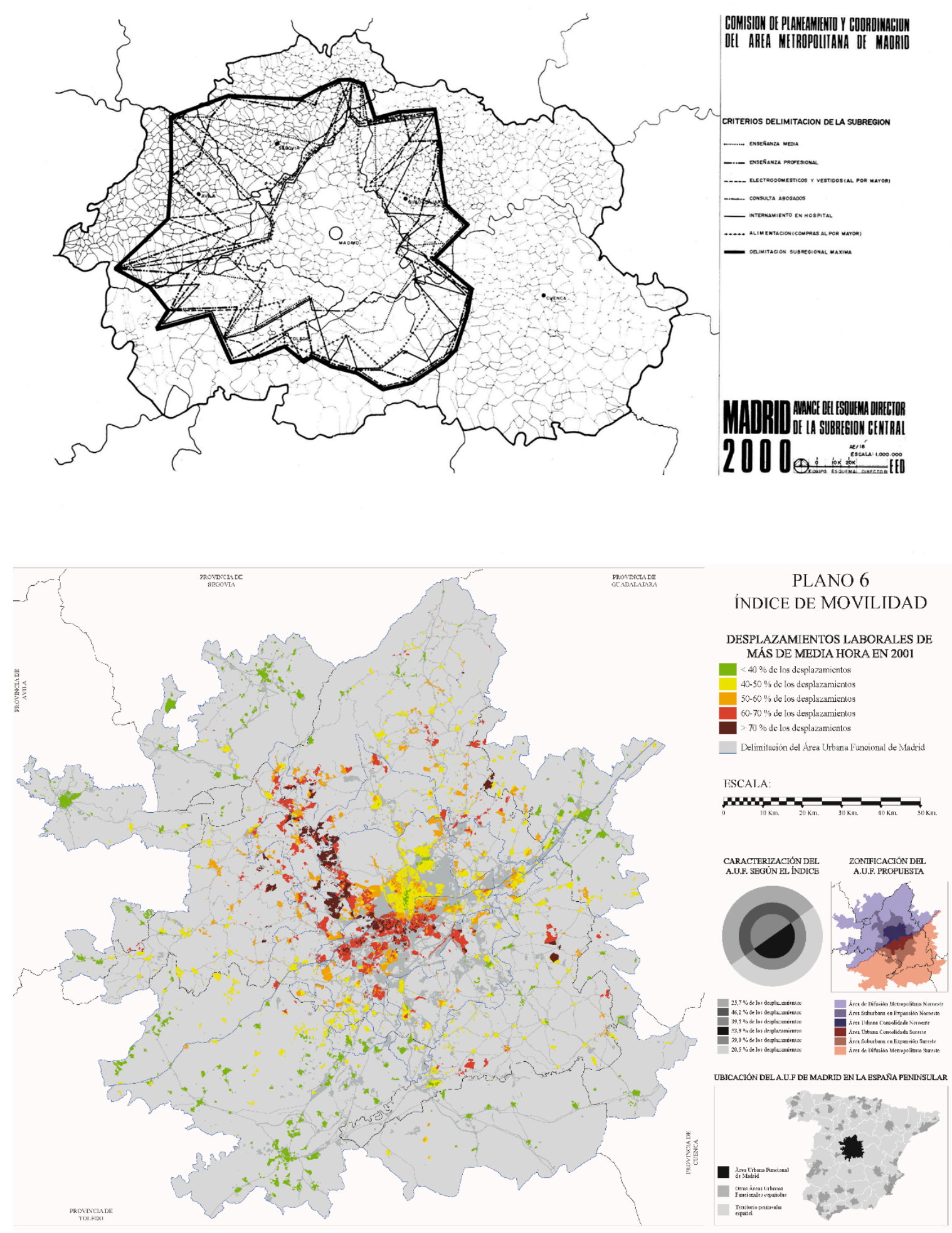

Figure 2. Throughout the last century, regional planning in the capital of Spain has not been completely alien to the attempts of multicriteria delimitation: above, graphic pertaining to the structural analysis of the "Madrid 2000" Scheme Director, 1971; below, commuting plan with statistical information of 2001 on the Functional Urban Area proposed by Madrid Council in 2014 (Terán, 1999, p.97; Gómez Giménez, 2017, p.17). 


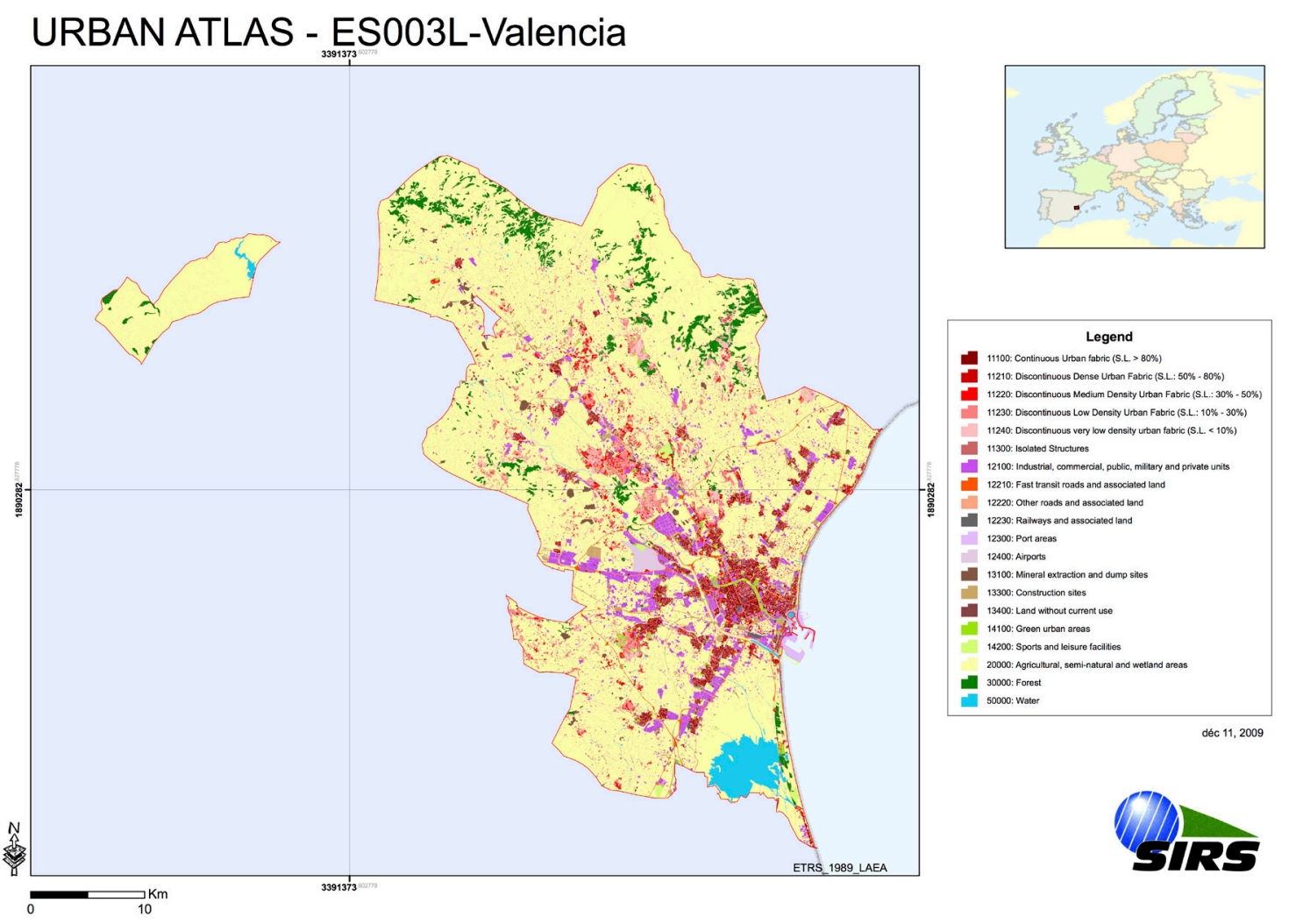

Figure 3. Valencia Functional Urban Area (ES003L2) according to the 2009 European Commission Urban Atlas, including an extraneous leapfrog area.

approximation of the urban center when this stretches far beyond the administrative city boundaries" (Dijkstra and Poelman, 2012).

As it can be observed, this attempt to standardize the way in which urban boundaries are established responds fundamentally to administrative criteria and to commuting patterns. Both concepts have served as the basis for important datasets such as the Urban Atlas (hereinafter, UA), a large set of highResolution digital land use and land cover maps covering more than 300 European Functional Urban Areas as defined by the Urban Audit. In fact, together with other mappings supported by the European Environment Agency, such as CORINE Land Cover (CLC) and the European Soil Layer (SSL), the UA is now an indispensable tool for urban studies in Europe (European Comission, 2011).

Other interesting initiatives have also been developed using these databases, such as the recent European Settlement Map (ESM) project, which uses very high-resolution satellite imagery combined with the general
GHSL - Global Human Settlement Layer methodology to support urban policy makers (Florczyk et al., 2016), or the attempt to integrate the MOLAND and Urban Atlas geodatabases (Ribeiro Barranco et al., 2014). All of them are important projects of the Joint Research Center of the European Commission, whose aim is to track urban growth changes systematic and consistently.

However, these valuable cartographies - as we have seen in the particular case of Spain - suffer from at least two important deficiencies. First, they omit the connection with the territorial scope of the respective instrument of planning, the key tool of metropolitan management. And secondly, but no less relevant, the fact that regardless of the dataset used, all maps are always adjusted to some indivisible minimum unit of a purely administrative character: an urban cluster, as defined by Urban Audit; The OECD-EC Functional Urban Areas, for the Urban Atlas mapping extent; or administrative units linked to ESM validation experiments.

In this sense, it is frequently mentioned 
that the coordination of these cartographies with other datasets, such as cadastral ones or those linked to building footprints (ex. Open Street Maps) would be desirable in order to obtain a detailed and adjusted Metropolitan characterization. It is worth noting that many municipalities concentrate their urban activity in a specific area of their land, however, they are fully integrated in the definition of the larger metropolitan area. Without a doubt, unless the administrative circumscriptions are transcended, we will not be able to effectively limit the Greater City. Only then will it be possible to fully understand and plan the real metropolis, in order to develop efficient planning instruments for its best possible functioning.

\section{Big data and new cartographies}

While defining the metropolis, the need of attending to spatial patterns - built-up areas, open spaces, geographical constraints, etc.seems undeniable, according to methodologies based on high-resolution satellite image (Inostroza et al., 2013). In addition, new cartographic possibilities linked to big data, such as the already described European ones and other statistical datasets (as included in the Spanish Digital Atlas of the Urban Areas of 2016: population, housing and real estate data, coverage, SIOSE, etc.), would enrich the spatial component.

Last but not least, the metropolitan delimitation should respond to the dynamic and changing character of cities: a dynamic quantification, related to the urban expansion trends and commuting patterns, that can not be measured with the use of static census data gathered for limited municipal boundaries.

All these projects include the creation of datasets with the use of satellite images as their basis - Statistics National Institute (hereinafter, INE), Cadastre, etc. -, whose potential is still to be exploited to a great extent because they are not "sufficient in terms of the resolution, thematic granularity, coverage or temporal span. None of the available products offers a wall-to-wall fine-scale and consistent representation of the built-up areas in Europe" (Florczyk et al., 2016).

In the case of Spain, the Municipal System of Indicators of Sustainability presents a series of references, essentially static, that can implement a solid base on which to combine the dynamic elements. In the first place, the occupation of the land or the definition of land uses, obtained from the data of the SIOSE and the cadastre, allows us to obtain a clear information of the quantity and degree of artificial soil created by the man, along the

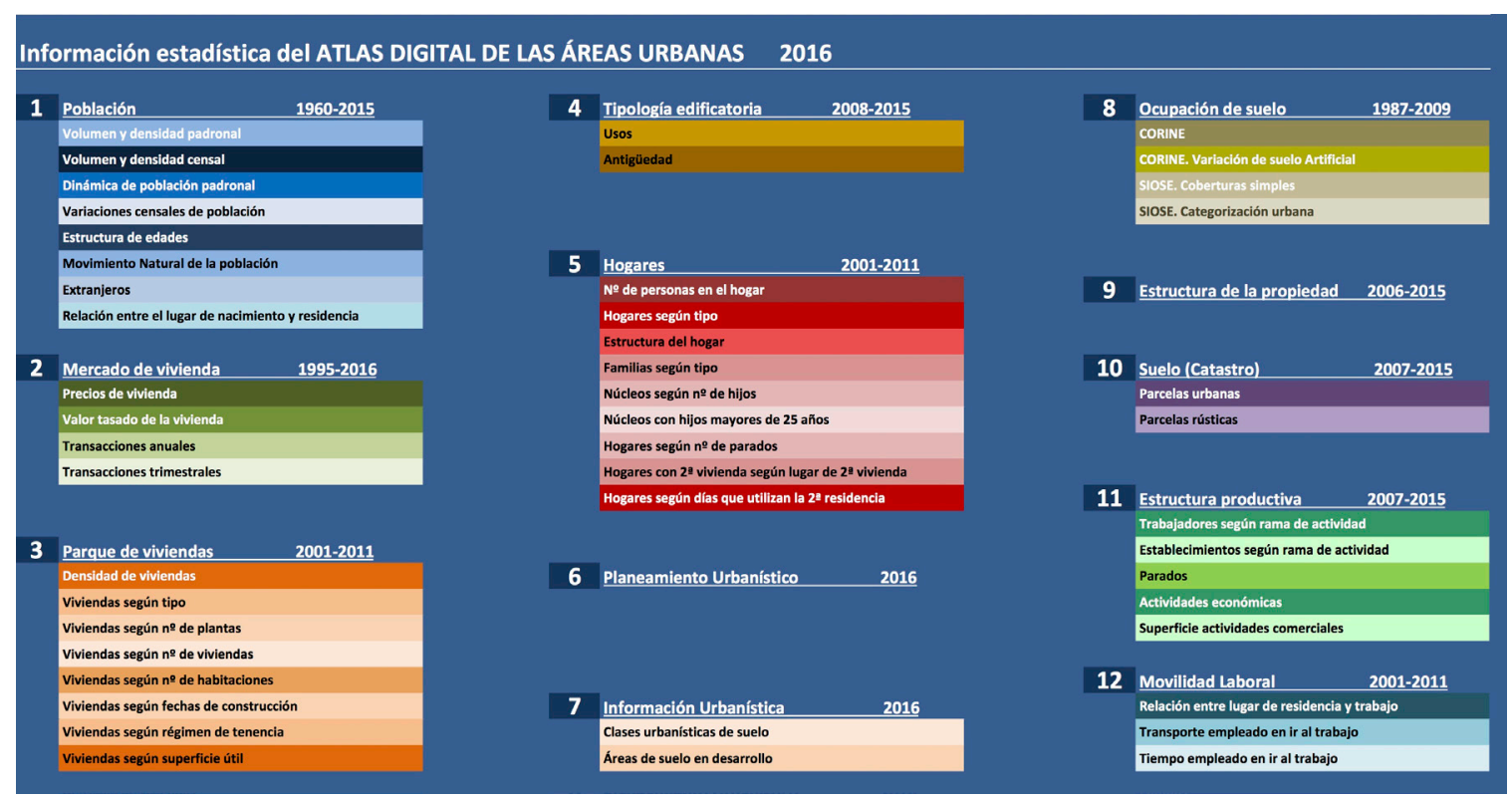

Figure 4. Statistical information considered in the 2016 Spanish Urban Areas Digital Atlas. 
lines of the European Urban Atlas or the ESM. In combination with this value, the density or intensity of use (present in the cadastre or in the INE censuses) allows not only to locate the built-up areas but also to quantify their intensity and thus their importance in the configuration of the region.

Apart from the intensity, using satellite images to determine the use of the built-up areas (available at the cadastral databases), can help identify polarized constructed areas with very specific uses. This allows establishing dependency relationships between exclusively residential areas (dormitory cities), commercial, industrial and office areas (workplaces) and mixed-use areas that are capable of offering the appropriate services for daily life. In this regard, the definition of public transportation networks and proximity indexes to bus stops, subways, bicycle lanes, etc., would allow a deeper understanding of the relationships between the different built areas. Studying the traffic maps of private vehicles that are contemplated in some way in the noise maps and INE databases could complement this mobility study.

The new satellite techniques and their potential when associated with census and statistical data have been very useful to map the city and its activity so far. However, the truth is that no current implemented tool is able to accurately measure the mobility of people and vehicles in a dynamic way, or in other words, with a sufficiently significant frequency of time to be able to understand the real activity of a metropolitan area as a whole.

In Spain, initiatives have been carried out at the municipal level to try to quantify mobility in urban areas of special interest in order to increase the efficiency of municipal planning (improved traffic in San Sebastian and telephone data in Barcelona). They respond, respectively, to two complementary methodologies:

Use of people and vehicle counters. Composed mainly by sensors or pneumatic road tube counters, they are useful to establish

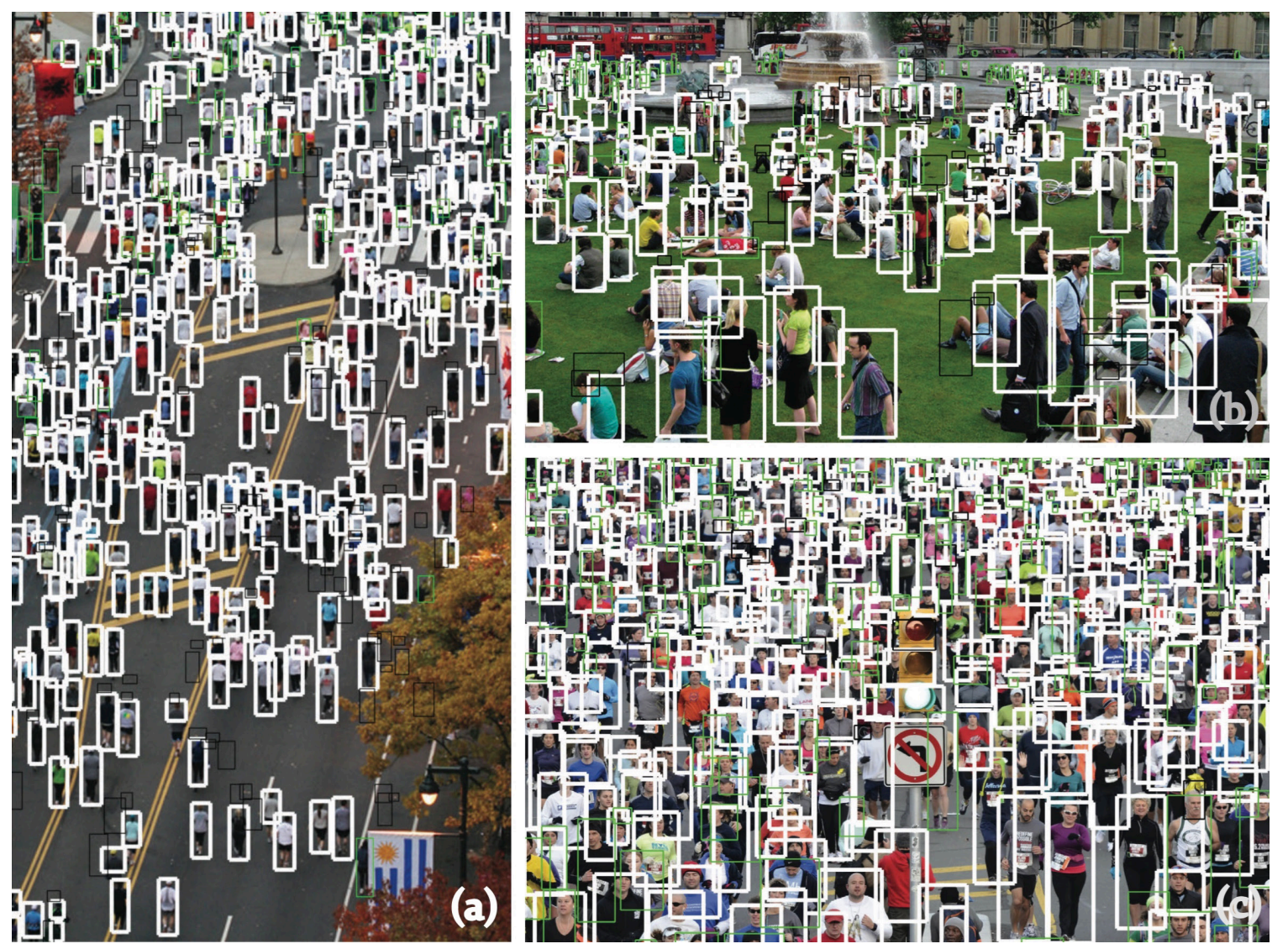

Figure 5. Human detection approaches through color bounding boxes in different scenarios (Idrees et al., 2015, p.1996). 
the Annual Average Daily Traffic, where the sum of the traffic activity of a whole year is divided among 365 to obtain the mean. It serves to determine the approximate number of vehicles, people or bicycles that make use of a track on a daily basis.

Crowd analysis. Usually employed in urban contexts with large influxes of people, in which the number of people and their speed are observed, making use of camera images. These are able to measure the number of people with the use of algorithms for image analysis. They have led to the development of mass behavior prediction techniques such as swarm intelligence, which serve to establish more efficient urban planning criteria.

These strategies have been proven useful while quantifying flows or densities in a particular road or area of the city, but lack a broad enough scope of study to encompass the urban or metropolitan scale. In addition, in many cases, these studies occur at specific times or with frequencies that do not extend over time (such as concerts or festivals in the case of crowd analysis, or a series of months in the case of vehicle counters). The combination of these two shortcomings makes these techniques insufficient to determine the real extent of urban activity.

However, the rise of cellphones and smartphones has generated a new series of techniques that are capable of approaching the measurement and representation of urban activity in a dynamic way. Due to the fact that these devices act as real time locators with a very high degree of disaggregation, it is possible to determine urban activity with unprecedented accuracy, scale and frequency. Attempts to develop a digital platform in which all the urban activity can be shown (also named real-time city) are of special interest, particularly the ones developed by the MIT Senseable City Lab. The way in which these platforms gather urban data is usually based on the use of smartphones to obtain information on the movement of people and vehicles in urban areas.

One of the first initiatives in this direction, developed precisely by this laboratory in 2014 is HubCab. It shows the trips made by New York
City taxi drivers over a year for each daily time slot. In addition, it shows where the passengers were picked up and where they were dropped off. Although real-time smartphone location was not used for this study (only pick-up and drop-off points), it is capable of showing which areas receive more influx of people throughout the day with a very large accuracy and with a general vision of the metropolitan area.

Another interesting example is the Waze application, which acts as a social traffic network. In it, users share traffic incidents through their smartphones to notify other drivers who also use the app. In this way, Waze is capable of suggesting the driver the fastest route to reach the destination according to the point where he is at on a real-time basis. It is worth noting that the technology giant Google paid approximately $€ 1$ billion for this company, in its quest to offer the best map service possible to represent the activity of cities in its platform.

On the other hand, Uber has recently joined these services with the launch of Uber Movement, the platform in which the information of its drivers over a year is shown. In it, you can observe the approximate travel times of the trips that the company makes in a series of cities. Along with these platforms, closer examples such as the collaboration between Euskaltel and the San Sebastian City Council under the European project Replicate (H2020), allow to understand the flow of people in the city in different timespans (throughout the day, week and months) thanks to the company's telephone data.

All of these tools, which currently demonstrate their potential in the measurement of city traffic, could be used to determine the physical reach of a city and its actual economic impact. In this sense, it is necessary to reflect the dynamic and changing nature of the metropolitan delimitation, beyond the administrative limits: the same citizens can reside, work and practice leisure in municipalities, regions or even different countries during the same day, and at the same time, vary their behavior patterns according to the day of the week or season of the year.

The growing number of partnerships between technology companies and local 


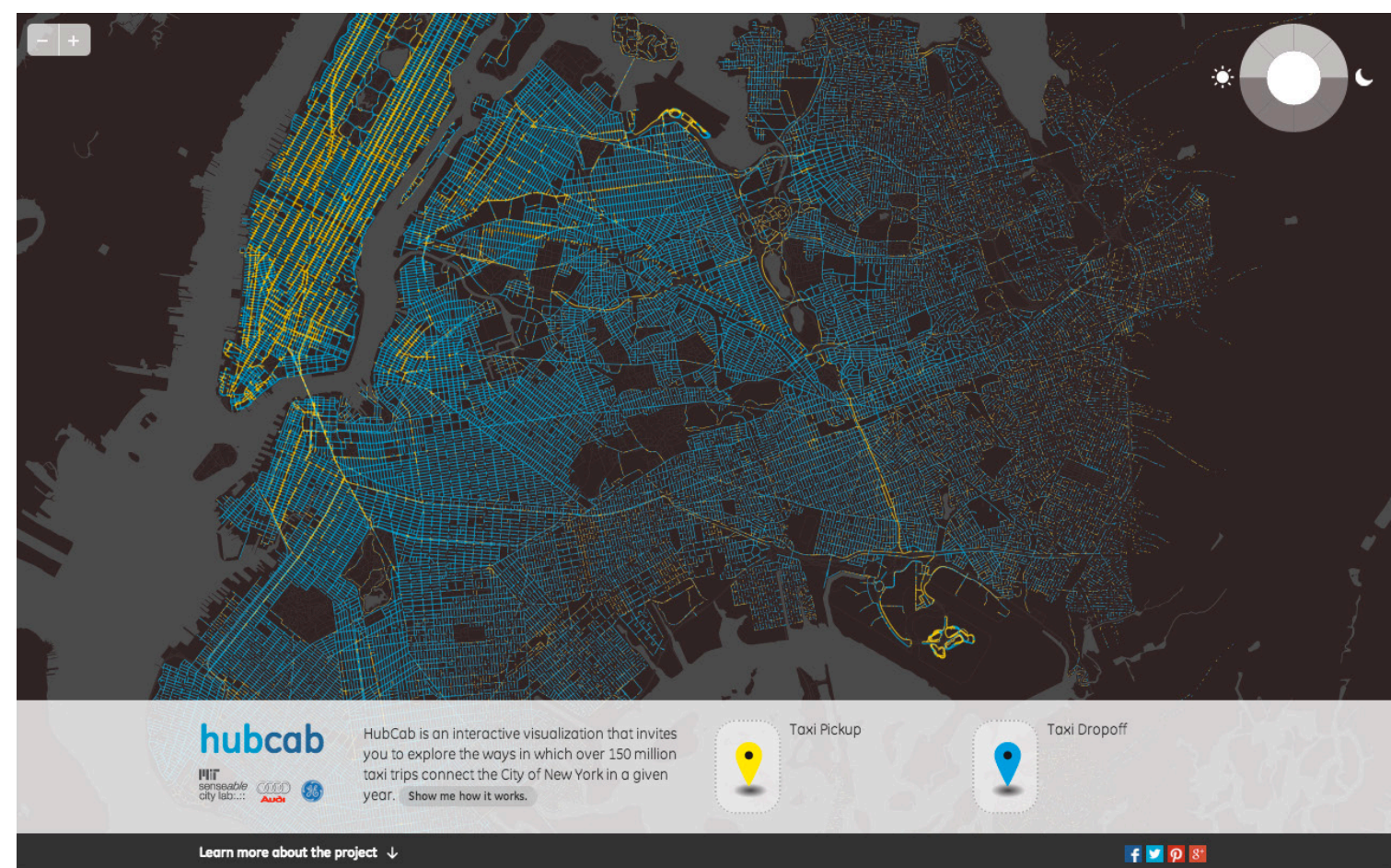

$\equiv$ UBER Movement

FAQS CONTACTUS

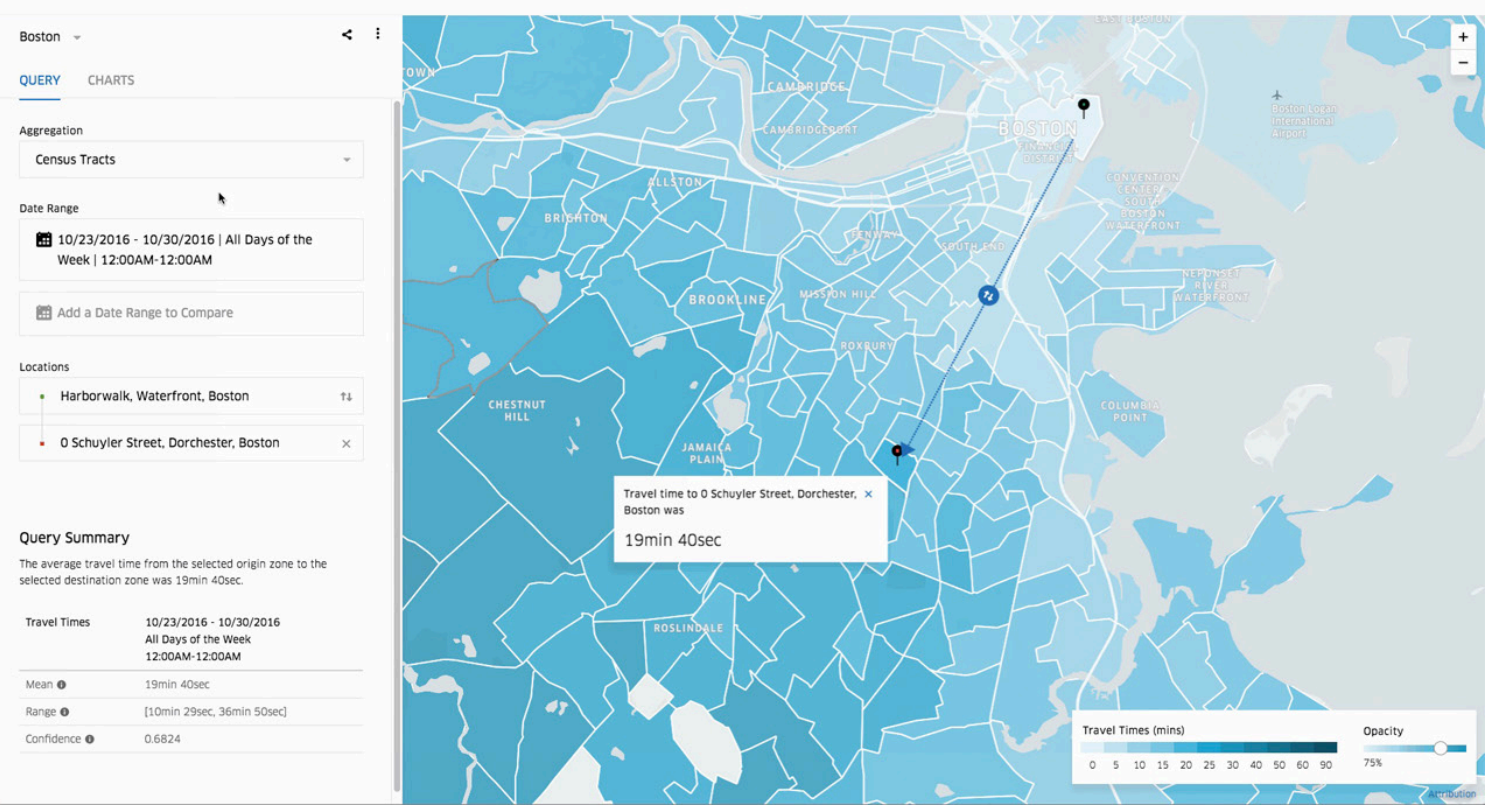

Figure 6. HubCab interactive visualization and Uber Movement display sample (MIT Senseable City Lab, 2014; Uber, 2017).

entities is emerging as the inevitable modus operandi of public administrations when it comes to understanding the way in which their cities work and what the actual reach of those cities is. Most probably, the debate on administrative boundaries is part of a political, rather than a technological sphere, but we should not lose sight of the fact that real-time information about our cities is the best current existing tool to show urban weaknesses and opportunities, and that these are precisely the challenges to which the administration should give an adequate response to. 


\section{Towards a data-based planning}

After reviewing the different approaches to characterize the metropolis, it is worth noting, first of all, the convenience of using a multilevel methodology while delimitating the Greater City. Combining the spatial component and layers of statistical information with highly disaggregated dynamic sensing databases seems the only efficient way to face the challenges of metropolitan management.

In the final analysis, the different layers of information - both spatial and statistical, both static and dynamic - would be merged to form a general map that could serve as a basis for territorial planning (Schmid, 2013, pp.408413). This result would generate a single maximum boundary for the metropolitan area, under which different types of delimitation could be established, depending on the planning purpose (ex. transportation, land use, waste treatment, etc.).

Although the legislative nature of land use planning implies a fixed consideration of all the layers - that is to say, the maximum boundary - as a field of action, in the face of a sectorial application, it would not be unreasonable to propose different combined planning boundaries for different planning purposes. To this end, the use of an urban planning authority that is superior to the local or even regional level that drives and leads the process is highly desirable: it is at this point were the maximum envelope can play a binding role in determining the number and proportional weight of the agents involved in the governance of the metropolitan area.

Finally, the dynamic nature of this databased methodology would require the creation of an open-access platform in which the collected information and the design of the algorithms that relates that data is as transparent and unbiased as possible. Areas that are currently affected by some of the levels of planning (metropolitan mobility, structural land classification guidelines, etc.) could one day not depend on this kind of management. On the other hand, municipalities that would contribute to the creation of that metropolitan authority in proportion to their demographic or labor weight could review their respective contributions to metropolitan planning economic or governance - according to their variable extent of the areas.

In summary, the incorporation of the new cartographic possibilities offered by big data and the digital collections (multi-sectorial mapping, satellite imagery, dynamic datasets) is presented as an incomparable opportunity for the planning of the territory, which until now has been historically linked to the administrative districts. This could reduce the existing and undesirable gap between the administrative and real metropolis and facilitate an efficient and sustainable management of our urban environments.

A clear thought in this regard is the fact that decisions at a municipal level many times lack the empirical data that justifies those decisions, and implementing these dynamic data-based approaches to understand the urban reality could strengthen the efficiency of urban policies. Technology, as this paper shows, is within our reach, but its application depends on the ambition of our authorities and policy makers. Today, more than ever, our cities require innovative techniques to face the tremendous challenges that they are experimenting throughout the world, from climate change, to socioeconomic inclusion. We encourage local administrations, and more specifically, the planning community, to rethink the way in which our cities are planned, according to the possibilities, challenges and opportunities of our time. The delimitation of real metropolis is just the first step.

\section{References}

Angel, S. (2016) Atlas of Urban Expansion [online]. Available from: http://www. atlasofurbanexpansion.org.

Brenner, N. \& Schmid, C. (2014) The 'urban age' in question. International Journal of Urban and Regional Research 38 (3), 731755.

Dijkstra, L. \& Poelman, H. (2012) Cities in Europe. The new OECD-EC definition [online]. Available from: http://ec.europa. eu/regional_policy/sources/docgener/ focus/2012_01_city.pdf. 
European Comission (2011) Urban atlas. Delivery of land use/cover maps of major European urban agglomerations [online]. Available from: https://www.eea.europa.eu/ data-and-maps/data/urban-atlas.

Feria Toribio, J. M. \& Martínez Bernabeu, L. (2016) La definición y delimitación del sistema metropolitano español: permanencias y cambios entre 2001 y 2011. Ciudad y territorio: Estudios territoriales 48 (187), 9-24.

Florczyk, A. J. et al. (2016) A New European Settlement Map from Optical Remotely Sensed Data. IEEE Journal of Selected Topics in Applied Earth Observations and Remote Sensing 9 (5), 1978-1992.

Gómez Giménez, J. M. (2017) El área urbana funcional de Madrid (19912011). Metodología y resultados de una propuesta de delimitación y caracterización multicriterio. Territorios en Formación 11, 113-23.

Hildenbrand, A. (2017) El abandono de la cuestión metropolitana en España. Revista Iberoamericana de Urbanismo 13.

Idrees, H. et al. (2015) Detecting Humans in Dense Crowds Using Locally-Consistent Scale Prior and Global Occlusion Reasoning. IEEE Transactions on Pattern Analysis and Machine Intelligence 37 (10), 1986-1998.

Inostroza, L. et al. (2013) Urban sprawl and fragmentation in Latin America: A dynamic quantification and characterization of spatial patterns. Journal of Environmental Management 115, 87-97.

Ministerio de Fomento (2013) Áreas Urbanas +50 . Información estadística de las Grandes Áreas Urbanas españolas 2012. María Dolores Aguado Fernández (ed.). Madrid: Centro de Publicaciones. Secretaría General Técnica.

Ribeiro Barranco, R. et al. (2014) Integrating the MOLAND and the Urban Atlas Geodatabases to Analyze Urban Growth in European Cities. Journal of Map and Geography Libraries 10, 305-328.

Roca Cladera, J. et al. (2012) El sistema urbano en España. Scripta Nova. Revista electrónica de Ciencias Sociales. XVI (396), 1-37.

Schmid, C. (2013) 'A Typology of Urban Switzerland', in Neil Brenner (ed.)
Implosions/Explosions. Towards a Study of Planetary Urbanization. Berlín: Jovis. pp. 398-427.

Terán, F. de (1999) Madrid: ciudad-región. Entre la Ciudad y el Territorio, en la segunda mitad del siglo XX. Madrid: Dirección General de Urbanismo y Planificación Regional, Comunidad de Madrid.

United Nations (2015) World Urbanization Prospects: The 2014 Revision. 